\title{
Sickness behavior in dairy cows during Escherichia coli mastitis
}

\author{
K. K. Fogsgaard, ${ }^{\star 1}$ C. M. Røntved, ${ }^{\star} \dagger$ P. Sørensen, $\ddagger$ and M. S. Herskin ${ }^{\star}$ \\ *Department of Animal Science, Faculty of Science and Technology, Aarhus University, PO Box 50, DK-8830 Tjele, Denmark \\ †CMR On-Site RD, Skjernvej 4A, DK-9220 Aalborg Øst, Denmark \\ ¥Department of Genetics and Biotechnology, Faculty of Science and Technology, Aarhus University, PO Box 50, DK-8830 Tjele, Denmark
}

\begin{abstract}
The consequences of mastitis in terms of dairy cow behavior are relatively unknown. Future assessment of dairy cow welfare during mastitis will be facilitated by knowledge about the potential of mastitis to induce sickness behavior. Our aim was to examine behavior of dairy cows in the period from $2 \mathrm{~d}$ before $(\mathrm{d}-2$ and -1$)$ to $3 \mathrm{~d}(\mathrm{~d} 0,1$, and 2$)$ after experimental intramammary challenge with Escherichia coli. Effects of experimentally induced mastitis on behavior were examined in 20 primiparous Danish Holstein-Friesian cows, all 3 to 6 wk after calving and kept in tie stalls. After evening milking on d 0, each cow received an intramammary infusion with 20 to $40 \mathrm{cfu}$ of $E$. coli in 1 healthy front quarter. Paraclinical and bacteriological examinations were conducted to confirm infection. Half of the cows were subjected to liver and udder biopsies twice during the trial. Behavior was video-recorded on 5 consecutive days, $\mathrm{d}-2$ to +2 after challenge when the cows were not disturbed by humans. The behavior of the animals was compared among all days. Infection with E. coli altered the behavior of the dairy cows. Time spent feeding was lower in the initial $24 \mathrm{~h}$ after infection compared with that on the other days $(16.6 \pm 1.1,16.5 \pm 1.0,13.2 \pm$ $1.2,18.1 \pm 1.1$, and $16.0 \pm 0.8 \%$ of time for $\mathrm{d}-2,-1$, 0,1 , and 2 , respectively). The duration of standing idle increased on d 0 compared with that on the control days and $d 1$ and $2(29.4 \pm 2.6,28.0 \pm 2.3,39.1 \pm 2.6$, $31.4 \pm 3.8$, and $25.9 \pm 2.6 \%$ of time for $\mathrm{d}-2,-1,0,1$ and 2 , respectively). The frequency of self-grooming behavior per hour decreased in the initial $24 \mathrm{~h}$ compared with that on $\mathrm{d}-2,-1$, and $2(4.1 \pm 0.8,5.4 \pm 1.9$, $3.2 \pm 0.6,3.6 \pm 0.6$, and $4.8 \pm 1.0$ for $\mathrm{d}-2,-1,0,1$, and 2 , respectively). Likewise, duration of rumination and frequency of turning the head against the udder decreased in the first days after infection (rumination: $32.2 \pm 1.6,34.8 \pm 1.8,27.9 \pm 1.7,30.0 \pm 2.6$, and 34.8 $\pm 1.7 \%$ of time; and frequency of turning head : $0.6 \pm$ $0.1,0.6 \pm 0.1,0.3 \pm 0.1,0.3 \pm 0.1$, and $0.6 \pm 0.1$ per
\end{abstract}

Received March 9, 2011.

Accepted September 28, 2011.

${ }^{1}$ Corresponding author: KatrineF.Jensen@agrsci.dk hour for $\mathrm{d}-2,-1,0,1$ and 2 , respectively). The cows subjected to biopsies showed an overall decreased lying time during the entire observation period $(36.3 \pm 1.5$ vs. $46.1 \pm 2.2 \%$ of time) but not directly related to the period after the biopsies. Dairy cows show classic signs of illness behavior in the hours after intramammary challenge with $E$. coli. This knowledge can be useful for the development of welfare assessment protocols, early disease detection, and for future work aimed at understanding the behavioral needs of dairy cows suffering from mastitis.

Key words: dairy cow, mastitis, welfare, sickness behavior

\section{INTRODUCTION}

The bovine mammary gland disease mastitis is the most widespread production disease among dairy cows worldwide (Bradley, 2002). Mastitis is associated with local or systemic clinical signs such as increased rectal temperature, changes in milk composition and yield, swelling and redness of the infected mammary glands, and might in severe cases lead to mammary atrophy. Furthermore, mastitis is believed painful, although the degree of pain is not known.

Behavioral changes during sickness have been reported in several animal species; however, most scientific evidence has focused on rodents (Aubert, 1999; Broom, 2006). Even though sickness behavior as such has not been studied much in farm animals, changes in different behaviors are linked to diseases (Urton et al., 2005; Gonzalez et al., 2008). Generally, invading pathogens initiate energy-demanding processes in the body, functioning to increase the effectiveness of the immune system to overcome the infection, for example, by increasing body temperature (Johnson, 2002). Consequently, energy will be switched from behavioral activities, such as feeding, social contact, or grooming (Johnson, 2002; Dantzer and Kelly, 2007), and sick animals might have a different set of behavioral priorities, leading to changes in the social and environmental needs of the individuals. Knowledge of illness behavior is an important foundation for future design of housing systems for sick dairy cows. 
At present, little is known of the consequences of bovine mastitis in terms of animal welfare; for example, whether infected animals should be housed or managed differently to optimize welfare throughout the illness and minimize potential pain. Previous studies of sickness behavior in dairy cows, during either naturally occurring or experimentally induced mastitis, have presented relatively small data sets and mainly focused on crude behavioral changes, showing that mastitis can lead to reduced rumination, reduced feeding time and intake, as well as changes in resting behavior (Gonzalez et al., 2008; Siivonen et al., 2011). Changes in normal behavior can indicate pain; changed activity, mental state, gait, vocalization, and posture are believed related to pain in dairy cows and other farm animals (Weary et al., 2006).

Our aim was to perform a detailed examination of behavioral changes in dairy cows with acute mastitis. In the days after an experimental intramammary challenge with Escherichia coli, elements of illness behavior and possible behavioral indicators of pain and discomfort were examined. Continuous video-recording of the behavior of dairy cows during 2 control days and $3 \mathrm{~d}$ after experimental induction of mastitis in 1 front quarter was conducted, and behavioral changes compared between days. Furthermore, behavioral changes were related to milk yield and selected clinical variables.

\section{MATERIALS AND METHODS}

\section{Animals and Feeding}

Twenty-four pregnant, Danish Holstein-Friesian heifers were transported to Research Center Foulum, Aarhus University, Denmark, at least 1 mo before calving. After calving, the cows were moved to experimental straw-bedded tie-stalls $(120 \mathrm{~cm} \times 200 \mathrm{~cm})$ with tethers of approximately $75 \mathrm{~cm}$. Each cow was kept with empty neighboring stalls. One week before initiation of the experiment, the cows were weighed $(\mathrm{BW}=557$ $\mathrm{kg} \pm 13)$ and body condition was scored $(3.1 \pm 0.1 ; 1$ to 5 scale; Kristensen, 1986). The cows were fed twice daily; at approximately 0800 and $1500 \mathrm{~h}$ using a TMR based on corn silage plus minerals and vitamins for ad libitum intake. The DMI (kg) was measured once daily, as remaining feed was removed and weighed before the next morning feeding. The cows were milked twice daily in the home stall at 0600 and $1700 \mathrm{~h}$. Prior to disease challenge, the general health status of all cows was monitored based on rectal temperature, white blood cell count (WBC), California Mastitis Test (score 1 to 5; Pyörälä, 2003; Kruuse, Marslev, Denmark), SCC, and bacteriological examinations of milk samples obtained just before the experimental challenge. Only animals with SCC $<27,000$ cells $/ \mathrm{mL}$ were included in the experiment. All procedures involving animals were approved by the Danish Animal Experiments Inspectorate and complied with the Danish Ministry of Justice's laws concerning animal experimentation and care of experimental animals. Inspection was carried out by members of the Danish Animal Experiments Inspectorate committee during the acute stage of the disease.

\section{Experimental Design}

The experiment was a longitudinal cohort study, with the individual dairy cow being its own control, examining the behavioral effects of experimental $E$. coli infection. For practical reasons, the cows were split into 3 successive blocks of 8 individuals each. Behavior of each cow was video-recorded continuously during a 120-h observation period from $2 \mathrm{~d}$ before $(\mathrm{d}-2$ and -1 ) until $3 \mathrm{~d}$ (d 0,1 , and 2) after experimental induction of mastitis. In this way, d 0 started at $1700 \mathrm{~h}$ (time 0 ) and lasted $24 \mathrm{~h}, \mathrm{~d} 1$ started at $24 \mathrm{~h}$ after infection, and $\mathrm{d} 2$ at $48 \mathrm{~h}$ and so on. Clinical and bacteriological examinations were conducted at regular intervals to confirm the presence of infection (Table 1).

\section{Experimental Induction of Mastitis}

The E. coli strain was a Danish field isolate, $\mathrm{k} 2 \mathrm{bh} 2$, isolated from cows with severe acute mastitis. All procedures involving handling of the $E$. coli inocula were conducted in a laminar airflow bench and under aseptic conditions. Before inoculation, each teat was disinfected twice with a cotton swab submerged with $70 \%$ ethanol. Each cow was inoculated with $10 \mathrm{~mL}$ of $0.9 \%$ pyrogenfree $\mathrm{NaCl}$ solution containing 20 to $40 \mathrm{cfu}$ of live $E$. coli, infused with a sterile teat cannula, in the front quarter with lowest SCC $(<27,000$ cells $/ \mathrm{mL})$. Five cows were inoculated in the right front teat and the remaining 15 cows in the left front teat. The procedure was carried out directly after evening milking (d 0 , time 0$)$.

\section{Data Collection}

Clinical and Bacteriological Data. Bacteriological and clinical examinations were conducted over several weeks as part of another study. Only the 5-d observational period was used in this study (Table 1). A sterile polyvinyl catheter was inserted into the jugular vein of all cows on $d-1$ for blood sampling. The catheters were flushed at each sampling, and at least once a day with a sterile $0.9 \% \mathrm{NaCl}$ solution containing 50 IU of Na-heparin (Loevens Kemiske Fabrik, Ballerup, Denmark). Rectal temperature was measured (Table 1). Four milk samples were collected daily for labora- 
Table 1. Timetable showing time of measurements during the 5 -d observation period ${ }^{1}$

\begin{tabular}{|c|c|c|c|c|c|c|}
\hline \multirow[b]{2}{*}{ Time } & \multicolumn{6}{|c|}{ Day } \\
\hline & -2 & -1 & 0 & 1 & 2 & 3 \\
\hline \multirow[t]{2}{*}{ 1700-1800 h milking } & Clinic & Clinic & Clinical/bacteriological & Temp, E. coli, SCC & Temp, E. coli & Temp, E. coli \\
\hline & $\begin{array}{l}\text { Behavioral recording } \\
\text { initiated }\end{array}$ & & E. coli infection & Udder/liver biopsy & & $\begin{array}{l}\text { Behavioral recording } \\
\text { terminated }\end{array}$ \\
\hline
\end{tabular}

$2100 \mathrm{~h}$

\section{$2400 \mathrm{~h}$}

0600 h milking

Clinic

$0900 \mathrm{~h}$

Vein catheter
Temp, E. coli, SCC Clinic, blood

Temp, E. coli, SCC

Temp, SCC, clinic Temp, E. coli, SCC Liver biopsy

Temp, E. coli, SCC Temp, E. coli, SCC
Clinic

Temp, E. coli, SCC Temp, E. coli, SCC

Clinic, blood

Clinic, blood

${ }^{1}$ Measurements of rectal temperature (temp), milk SCC, and milk Escherichia coli (E. coli) are used in the present study. Measurements of clinical variables (clinic), blood samples (blood), and biopsies were part of another study; data not included.

Table 2. Ethogram of behavior of dairy cows during the days before and after experimental induction of mastitis

\begin{tabular}{ll}
\hline Behavior & Definition \\
\hline The cow is disturbed & A human is present in the resident or neighboring stall or the cow is milked or tightly tethered \\
Undisturbed & The cow is not disturbed \\
Standing & The cow stands on 4 feet \\
Lying $^{1}$ & The body is resting in the stall \\
Lying down $^{\text {Lying on right side }}{ }^{2}$ & From kneeling until lying down with the body resting in the stall (Niss et al., 2009) \\
Lying on left side & Lying on the right side as seen from behind the cow \\
Head high & Lying on the left side as seen from behind the cow \\
Head supported while lying ${ }^{2}$ & The cow is lying on the sternum and the neck is raised, not touching floor or fixture (Krohn and Munksgaard, 1993) \\
Head bent while lying ${ }^{2}$ & The cow is lying on the sternum, with at least 1 point of the head touching the floor or fixture \\
Feeding behavior & The cow is lying on the sternum, the head is turned backward and rests on body or floor (Krohn and Munksgaard, 1993) \\
Drinking & Chewing or poking the feed with the muzzle; disruptions $\leq 10 \mathrm{~s}$ are ignored \\
Rumination & The tip of the muzzle is in the drinking bowl; disruptions $\leq 5 \mathrm{~s}$ are ignored \\
& Regurgitation, chewing, and swallowing of previously eaten food (Krohn and Munksgaard, \\
Leaning & 1993); bouts of $\leq 10 \mathrm{~s}$ are ignored and disruptions $\leq 10 \mathrm{~s}$ are allowed \\
Neck rested against fixture & The cow presses the forehead or muzzle against any fixture; bouts $\leq 30 \mathrm{~s}$ are ignored (Krohn, 1994) \\
Idle & The lower side of the neck is resting on the fixtures of the stall when the cow is in standing position; bouts $\leq 30 \mathrm{~s}$ are ignored \\
Frequency of self-grooming & The cow is standing, not performing any of the behaviors from the ethogram \\
Frequency of head against udder & Rubbing parts of the body or head against other body parts or fixtures of the stall, or licking body parts \\
\hline
\end{tabular}

${ }^{1}$ Lying and standing preclude each other and all other behavioral patterns are recorded in 1 of these 2 positions. Only 1 side and 1 head position is possible at a time, although other behavioral patterns can be recorded during these positions. All other behavioral patterns are mutually exclusive.

${ }^{2}$ Can only be measured when cow is in a lying position. 
tory analyzes. Milk SCC from the infected quarter was quantified using DeLaval DCC (Tumba, Sweden). To quantify E. coli $(\mathrm{cfu} / \mathrm{mL})$ and to rule out the presence of other mastitis-causing pathogens, $10 \mathrm{~mL}$ of foremilk was aseptically collected from the E. coli quarter $(\mathrm{Bu}-$ itenhuis et al., 2011). Samples of liver (Vels et al., 2009) and udder tissue (from the E. coli infected quarter and the matching control quarter; Buitenhuis et al., 2011) were collected on d 0 (liver biopsies at 13 and $24 \mathrm{~h}$ after inoculation; udder biopsies at $24 \mathrm{~h}$ after inoculation) from half of the animals as part of another experiment. The animals received sedation and local anesthesia during sampling of the liver and udder biopsies. All liver samples were collected from the right side of the cow, whereas the udder biopsies were collected from both sides. Cows subjected to biopsies were equally distributed between cows infused with $E$. coli in the left or right front quarter.

Behavioral Observations. Behavioral data were collected using 2 video cameras positioned above each cow, allowing full view of the animals from front and behind. Data were obtained using MSH Video Client (version 5.0.11.136, M. Shafro \& Co, Riga, Latvia). Dairy cow behavior was obtained continuously during the 120 -h period by 5 trained observers, ensuring that behavior of individual cows was always observed by the same person. Handling time and amount of disturbance varied between individuals. Therefore, behavior was only recorded when cows were undisturbed by humans and no humans were present in the resident or neighboring tie-stall. Likewise, milking time and periods where the cows were tightly tethered were excluded. Table 2 shows an ethogram of the recorded behavioral patterns.

\section{Statistical Analysis}

Three cows were excluded from the experiment because they did not meet the inclusion criteria, and 1 cow did not test positive for E. coli. All 4 cows were excluded from the statistical analysis, leaving a total of 20 animals. The proportion of time spent on a certain behavior as a percentage of the total undisturbed time was calculated and used for analyses. The occurrence of behavioral events was expressed as the frequency of events registered during undisturbed hours of each day. Leaning and head against fixture were excluded because of very few or no observations. Data are reported as means $\pm \mathrm{SE}$ and considered significant when $P$-values were $\leq 0.05$ and as a tendency when $0.05<P \leq 0.1$.

Behavioral Data. The frequency and duration of the observed behavioral traits were analyzed as continuous dependent variables in a mixed model including the repeated-measures statement in PROC MIXED of SAS (v. 9.1, SAS Institute Inc., Cary, NC). Block number $(1,2,3)$, biopsy status (yes, no), and day $(-2,-1$, $0,1,2)$ were included as fixed effects. The interaction between day and biopsy status was included if $P \leq$ 0.05. In the model for lying side (right or left), only animals inoculated in the left side of the udder were included $(\mathrm{n}=15)$. No analyses were conducted for right-side-inoculated animals because of the low sample size $(\mathrm{n}=5)$. Measurements at different time points for the same animal were assumed correlated, leading to the use of either a compound symmetric or a firstorder autoregressive covariance structure. The choice of covariance structure was determined based on the best fit assessed using the Akaike's information criterion (lowest values preferred; 9.1, SAS Institute Inc., Cary, NC). A logarithmic or square root transformation of the behavior traits was used to improve residuals in terms of variance homogeneity and dispersion based on visual examination of residual plots. In the case of significant differences between days, a pair-wise comparison of means for the days of interest was conducted in SAS (v. 9.1, SAS Institute Inc.). The same modeling approach was used for DMI, taking day and block number into account. Throughout, $P$-values were based on the Satterthwaite approximation for the denominator degrees of freedom.

Clinical Data. Correlations between clinical and behavioral variables were examined for $\mathrm{d} 0$ and 1 . The clinical traits milk SCC $(\mathrm{SCC} / \mathrm{mL})$, rectal temperature $\left({ }^{\circ} \mathrm{C}\right)$, and milk yield (L) at morning milking on $\mathrm{d} 0$ and 1 (12 and $36 \mathrm{~h}$ after infection) were correlated with the 5 behavioral traits that showed significant changes during the first $48 \mathrm{~h}$ after infection: (1) duration of feeding, (2) duration of rumination, (3) duration of idling, (4) frequency of self-grooming, and (5) frequency of head against udder. Analyses were made using Spearman rank order correlation $\left(\mathbf{r}_{s}\right)$ in SigmaPlot (v. 11, Systat Software Inc., San Jose, CA). The SCC and rectal temperature were recorded at h $0,3,6,12,18,24$, and 36 . The behavioral variables for this analysis were calculated as the sum of the behavior in a 1.5 -h period before and after collection of the clinical samples. Milk yield was correlated with behavior, summed over the 12 $\mathrm{h}$ before each milking.

\section{RESULTS}

The behavior of the dairy cows changed after induction of mastitis. All cows included in the data set tested positively for $E$. coli bacteria, and the low dose of $E$. coli used resulted in acute clinical mastitis, confirmed 


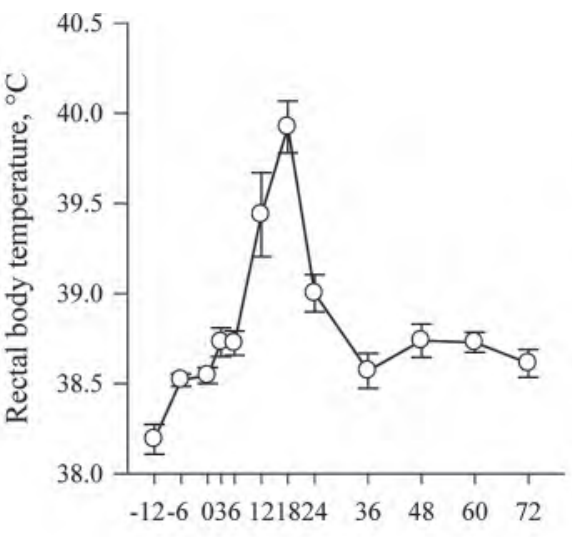

Time relative to infection, $\mathrm{h}$

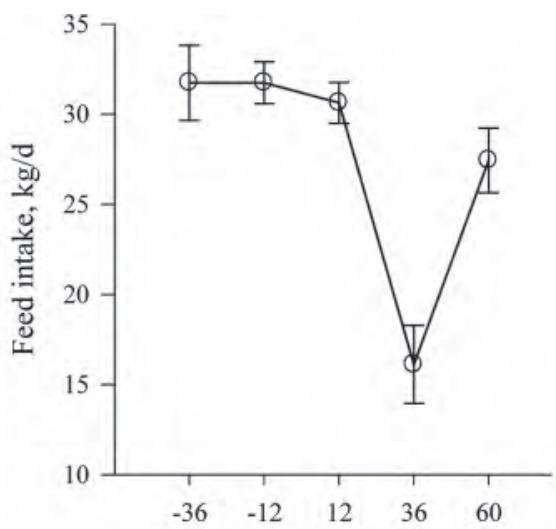

Time relative to infection, $\mathrm{h}$

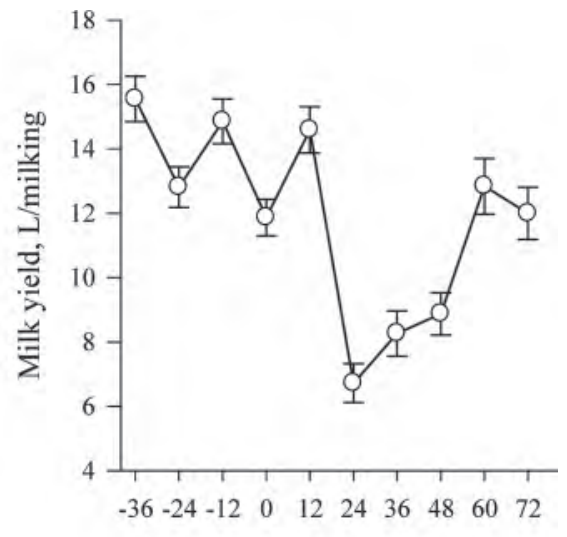

Time relative to infection, $\mathrm{h}$

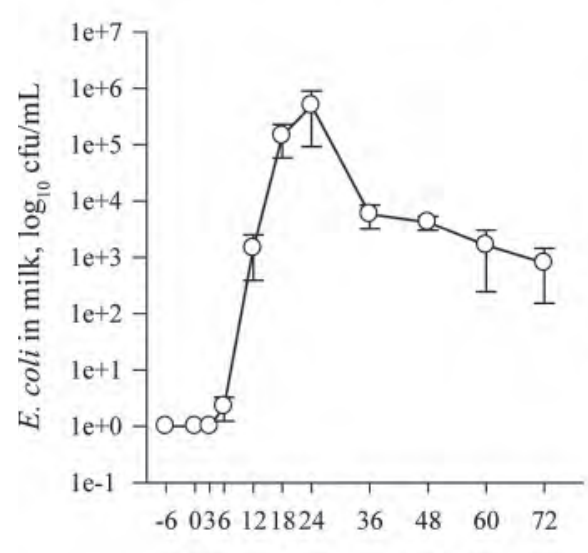

Time relative to infection, $\mathrm{h}$

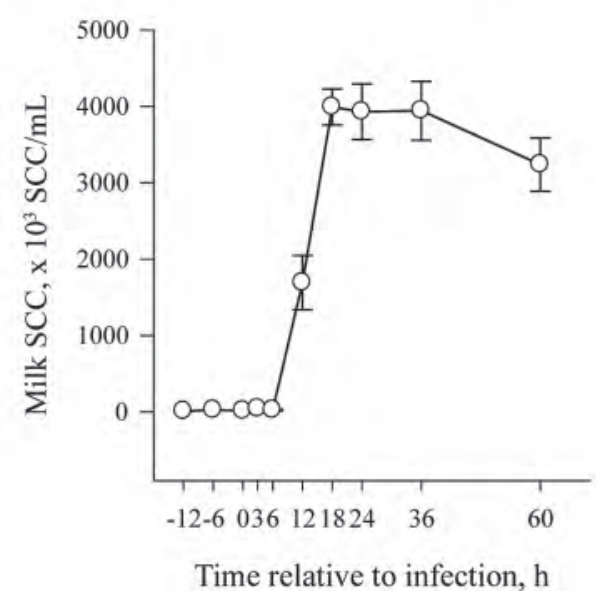

Figure 1. Changes in rectal temperature, feed intake, milk yield, Escherichia coli count in milk, and milk SCC from 20 Holstein-Friesian cows inoculated with $E$. coli in 1 front quarter at 0 h. Error bars show SE.

by the variation in rectal temperature, DMI, number of $E$. coli in milk, milk yield, and milk SCC during the observation period (Figure 1).

\section{Duration of Disturbance}

The duration of time excluded per day due to human disturbance ranged from $46 \mathrm{~min}$ to $16 \mathrm{~h} 41 \mathrm{~min}$, with a mean of $194 \pm 14 \mathrm{~min}$, and was affected by day $\left(F_{4}\right.$, $61.1=4.78 ; P=0.002)$, showing that the cows were less disturbed on $\mathrm{d}-2$ compared with $\mathrm{d}-1,0$, and 1 , and less disturbed on $\mathrm{d} 2$ than on $\mathrm{d} 0$.

\section{Behavioral Differences Between Days}

Figure 2 shows the significant behavioral changes between days. On d 0 and 1 , the frequency of turning the head against the udder per undisturbed hour was lower than on $\mathrm{d}-2,-1$, and $2(P \leq 0.04)$. The frequency of self-grooming behavior per hour was lower on $\mathrm{d} 0$ compared with that on the control days and $\mathrm{d}$
$2(P \leq 0.005)$. The cows spent more time idling on $\mathrm{d}$ 0 compared with the other days $(P \leq 0.001)$ and less time feeding compared with that on $\mathrm{d}-2,-1,1$, and 2 $(P \leq 0.02)$. The duration of ruminating was lower on $\mathrm{d}$ 0 compared with that on $\mathrm{d}-2,-1$, and $2(P \leq 0.03)$, and on $\mathrm{d} 1$, the duration of rumination was decreased compared with that on d $2(P=0.01)$. Lying behavior and lying on the left side were more abundant on $\mathrm{d}$ 2 compared with all other days $(P \leq 0.04)$. No other behavioral variables differed significantly between the $5 \mathrm{~d}$. The DMI was decreased in the period from 12 to $36 \mathrm{~h}$ after infection compared with all other periods $(P \leq 0.001 ;$ Figure 1), and lower in the period 37 to $60 \mathrm{~h}$ after infection compared with the 2 preinfection measurements $(P=0.02$ and $P=0.02)$.

\section{Effect of Biopsies}

The interaction between biopsy status and day was excluded from all models $(P>0.05)$. Figure 3 shows the behavior of the animals by biopsy status. Throughout 
Head against udder

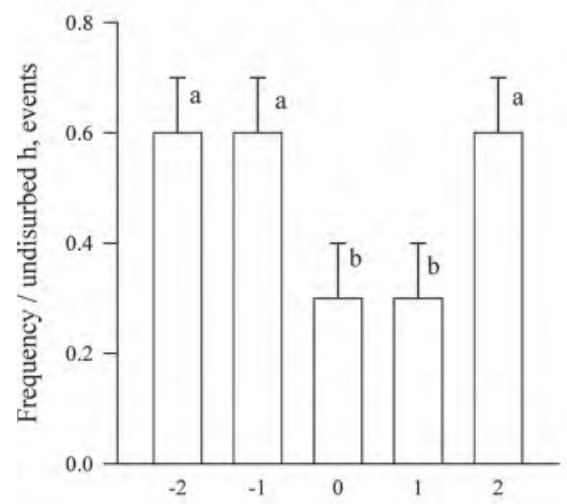

Feeding

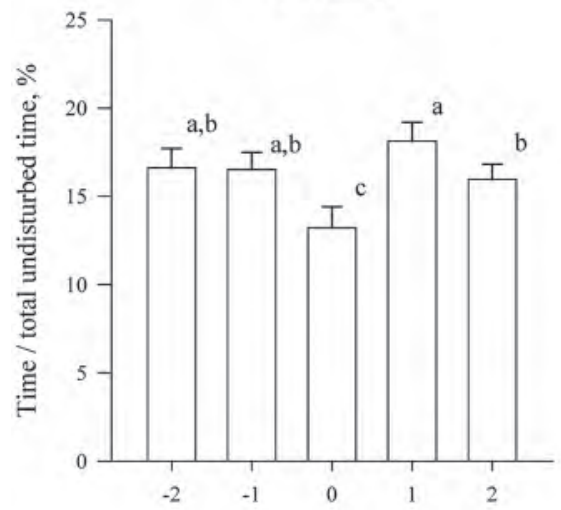

Time relative to infection, $\mathrm{d}$
Self-grooming

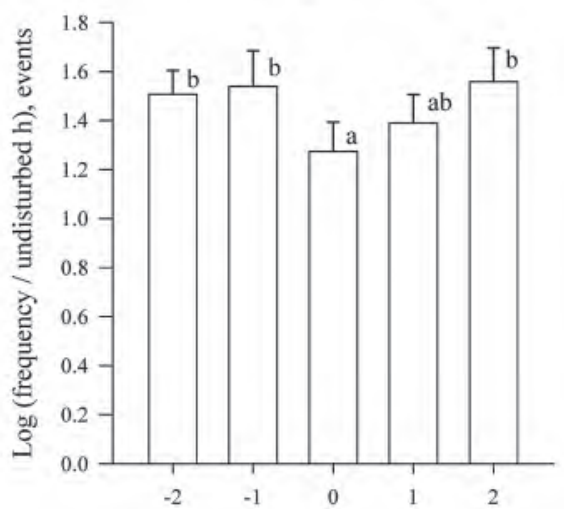

Rumination

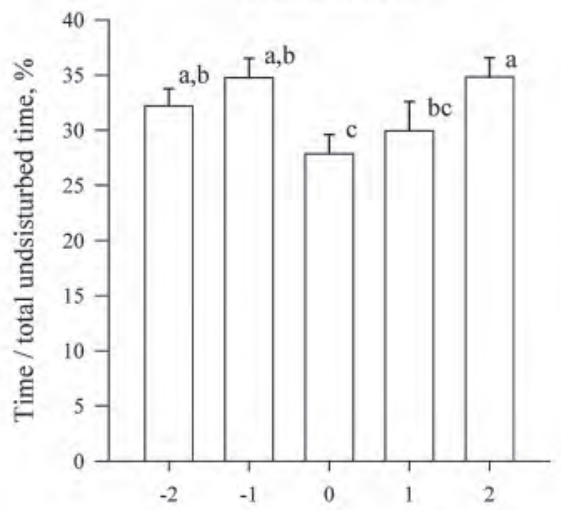

Time relative to infection, $\mathrm{d}$
Idle

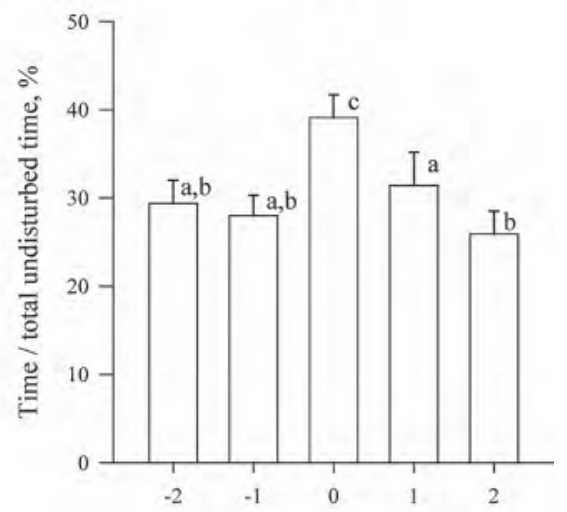

Lying

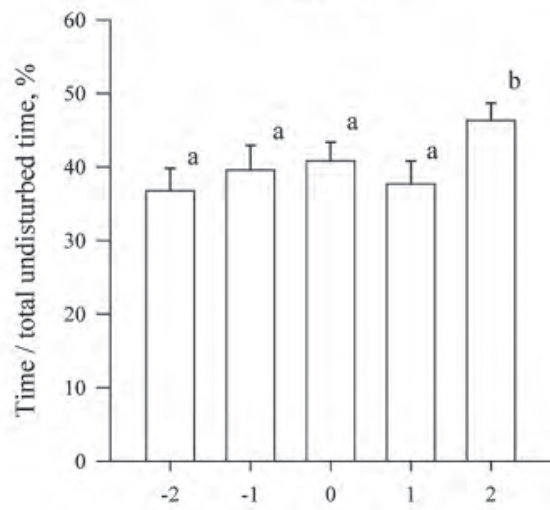

Time relative to infection, $\mathrm{d}$

Figure 2. The plots show the mean daily behavior in 20 Holstein-Friesian cows recorded during 2 consecutive control days $(-2$ and $-1 ;-48$ $\mathrm{h}$ to $-1 \mathrm{~h}$ ), followed by 3 experimental days $(0,1$, and $2 ; 0$ to $+72 \mathrm{~h})$ after induction of Escherichia coli into 1 quarter at the beginning of $\mathrm{d} 0$ $(0 \mathrm{~h})$. Plots with different letters differ significantly. Error bars show SE.

the data set, the only behavioral variable significantly affected by biopsy status was lying time $\left(F_{1,16}=4.53\right.$; $P=0.05)$, indicating a lesser duration of lying for cows subjected to biopsies on all observation days. Overall, the lying time for cows subjected to biopsy was 36.3 $\pm 1.5 \%$ of the undisturbed time per day, whereas cows without biopsies were lying down for $46.1 \pm 2.2 \%$ of the time. Furthermore, on all observation days, cows subjected to biopsies spent less time lying on their left side (17.1 vs. $27.9 \%$ ) compared with the nonbiopsied cows $\left(F_{1,11}=6.65 ; P=0.02\right)$, but as with lying time, no interaction between biopsy status and day was found.

\section{Correlations Between Clinical Data and Behavior}

Of the 80 calculated correlation analyses, 5 were significant. Rectal temperature measured after $12 \mathrm{~h}$ was correlated with time spent lying for $3 \mathrm{~h}$ from 10.5 to $13.5 \mathrm{~h}$ after infection $\left(\mathrm{r}_{s}=0.47 ; P=0.04\right)$ and nega- tively correlated at $24 \mathrm{~h}$ with frequency of head against udder for $3 \mathrm{~h}$ from 22.5 to $25.5 \mathrm{~h}$ after infection $\left(\mathrm{r}_{s}\right.$ $=-0.45 ; P=0.05)$. Milk yield at $36 \mathrm{~h}$ after $E$. coli challenge was correlated with time spent ruminating for $12 \mathrm{~h}$ from 24 to $36 \mathrm{~h}$ after infection $\left(\mathrm{r}_{s}=0.54 ; P\right.$ $=0.02$ ) and the frequency of self-grooming behavior in the same period $\left(\mathrm{r}_{s}=0.45 ; P=0.05\right)$. Correspondingly, milk yield at $36 \mathrm{~h}$ was correlated negatively with the time spent idling $\left(\mathrm{r}_{s}=-0.47 ; P=0.04\right)$.

\section{DISCUSSION}

This examination of the effect of experimentally induced E. coli mastitis on dairy cow behavior confirmed that dairy cows show classical signs of sickness behavior when suffering from acute, clinical mastitis. In the initial $24 \mathrm{~h}$ after infection, the dairy cows showed increased idling, spent less time ruminating and feeding, performed a lower frequency of self-grooming behavior 

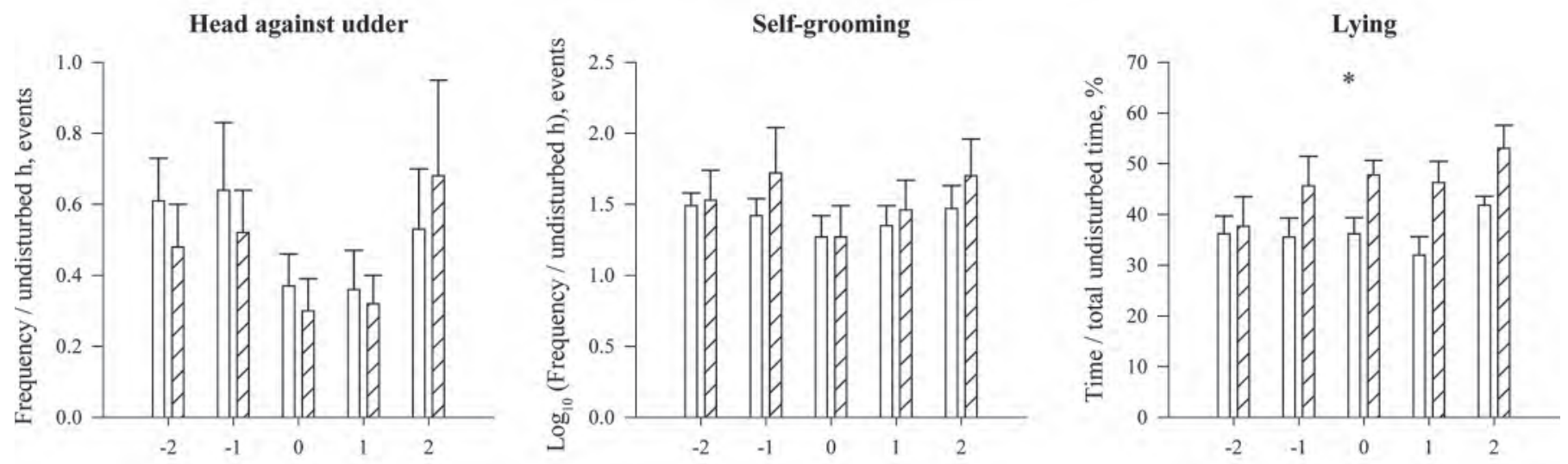

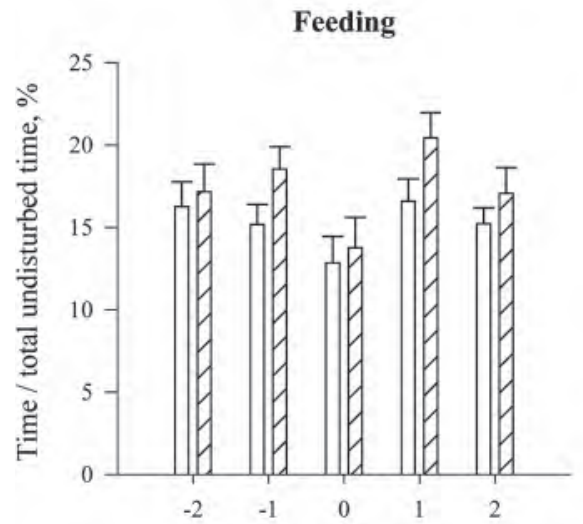

Time relative to infection, $\mathrm{d}$

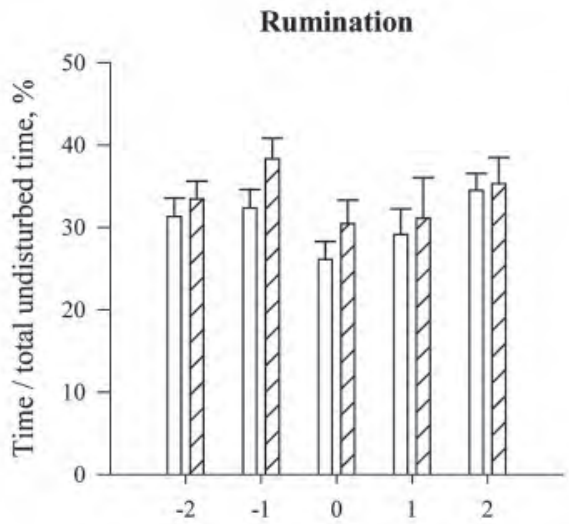

Time relative to infection, $\mathrm{d}$

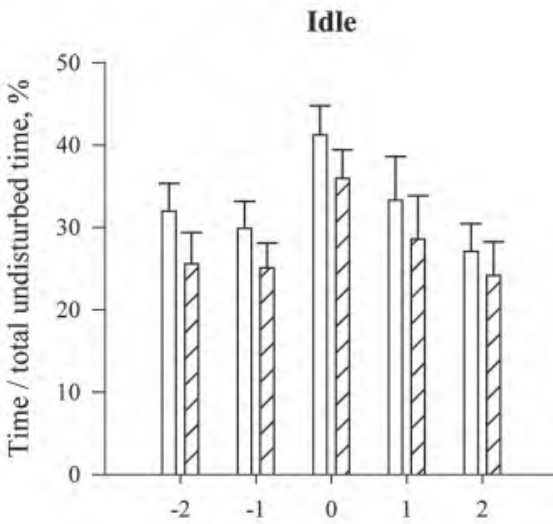

Time relative to infection, $\mathrm{d}$

Figure 3. The plots show the mean daily behavior of a total of 20 Holstein-Friesian cows registered during 5 experimental days with induction of Escherichia coli into 1 quarter at the beginning of d $0(0 \mathrm{~h})$. The data are split up by biopsy status: half the cows were subjected to biopsies at 13 and $24 \mathrm{~h}$ postinfection. The behavior of the biopsied cows did not differ from that of the nonbiopsied cows $(P>0.1)$, except in lying time, where the biopsied cows had an overall reduced lying time compared with the nonbiopsied cows $(P<0.05)$. The differences between days can be seen in Figure 2 and are not shown here. Error bars show SE.

and turning the head against the udder compared with the days before infection and after recovery. Furthermore, the behavioral responses correlated with clinical symptoms of mastitis, such as milk yield and rectal temperature. These results might form the basis for future studies of motivational and preferential changes in dairy cows during mastitis.

Feeding time decreased only a few hours after inoculation with $E$. coli and remained lowered during the initial $24 \mathrm{~h}$, suggesting that even under environmental conditions where feed is easily accessed, feeding is a behavior affected during illness. In addition, DMI decreased in this period. These results support Vels et al. (2009), who showed an initial decrease in feed intake and a return to normal levels within $48 \mathrm{~h}$ in LPS-infused dairy cows, and Bareille et al. (2003), who showed decreased DMI in dairy cows with spontaneously arising local and systemic mastitis. Other reports using similar or higher doses of $E$. coli were not able to show effects of mammary $E$. coli infection on DMI (Barrett et al., 1997), which might indicate that DMI is sensitive to the course of the disease, as proposed by Gonzalez et al. (2008), and is not suited for mastitis detection without support from other variables.

The frequency of self-grooming decreased in the initial $24 \mathrm{~h}$ after challenge, and detailed hour-by-hour analysis (data not shown) showed that this pattern persisted until approximately $35 \mathrm{~h}$ after infection. Grooming behavior serves to keep the body surface clean and remove ectoparasites. During disease, a reduced level of activity reserves energy for the increased metabolic cost of fever (Hart, 1988). Reduced self-grooming might be a 
secondary effect of the general increased inactivity, but has been suggested to serve directly to minimize heat loss from the body surface and water loss through saliva (Hart, 1988). Earlier studies have shown similar shortlasting decreases in self-grooming after i.v. injection of LPS in other animal species (e.g., goats; Takeuchi et al., 1995). The present results suggest that decreased self-grooming can be associated with sickness behavior in cows as well.

Lying behavior is highly prioritized in cattle (Jensen et al., 2004). Based on the use of operant conditioning techniques, heifers have an inelastic demand for lying of 12 to $13 \mathrm{~h} / \mathrm{d}$ (Jensen et al., 2005). In the present study, the average lying time during control days was a little lower, at $<40 \%$ of the time. This difference might be due to human handling and disturbance in the experimental barn. In general, lying is often increased during illness (Johnson, 2002; Broom, 2006), where the reduced activity is considered beneficial for energy conservation and maintenance of the febrile response (Johnson, 2002). In contrast, Siivonen et al. (2011) described a decrease in lying behavior during the initial days of LPS-induced mastitis in dairy cows, and suggested that the local clinical symptoms of mastitis, such as swelling and redness of the udder, explained this unexpected change in behavior. During the acute stage of mastitis, lying behavior might be aversive and may consequently be avoided in spite of the illness-induced enhanced lying motivation (Dantzer and Kelly, 2007). Because of high lying time in dairy cows, the observed changes in the duration of lying may be an indicator of coping difficulties in response to the disease (Ito et al., 2010; Siivonen et al., 2011).

Liver and udder biopsies were collected from half of the experimental animals as part of another study examining metabolic consequences of mastitis. Vels et al. (2009) showed that similar biopsy procedures did not affect WBC, DMI, SCC, body temperature, or milk yield of healthy cows or cows with LPS-induced mastitis. In the present study, effects of biopsy status on the behavioral variables were accounted for in the statistical analyses. Biopsied animals had reduced lying time during the entire experiment (even before the biopsies). This unexpected finding is considered an artifact, because the only difference between biopsied and nonbiopsied cows was the biopsy procedure itself. To date, only one study has investigated the effect of liver biopsies on dairy cow lying behavior, with results suggesting that the procedure can lead to pain in the initial hours postbiopsy (Moelgaard, 2010). In the present study, no clear effect of biopsy status could be shown on other dairy cow behaviors.
No direct measurements of pain from mastitis could be drawn from the present study. Mastitis is expected to be a painful condition for dairy cows (Leslie et al., 2010 ) and is associated with symptoms of pain in other species, such as pigs (Gerjets and Kemper, 2009). Lohuis et al. (1988) observed that dairy cows challenged with $20 \mathrm{~mL}$ of $0.9 \%$ pyrogen-free $\mathrm{NaCl}$ solution containing $10^{5} \mathrm{cfu}$ E. coli and not administrated antiinflammatory drugs became more restless and kicked the udder more than cows treated with dexamethasone. Furthermore, changes in thermal and mechanical nociceptive thresholds, as a sign of altered pain sensitivity, have been reported (Milne et al., 2003). If pain is present, the cows might direct attention toward the udder, trying to alleviate the pain by licking or grooming the udder. The behavior "head against the udder" was expected to be an intentional movement to lick or groom the udder. The frequency of head against udder declined in the initial $48 \mathrm{~h}$ after infection. One explanation for this unexpected finding is that the general responsiveness of the dairy cows was reduced due to the mastitis (Rasmussen et al., 2011). Another possibility is that head against udder is not a behavioral attempt to alleviate pain, but a normal self-grooming behavior, which would then be expected to decline during illness (Hart, 1988).

In general, when sickness is accompanied by pain, an underlying motivational conflict between sicknessmotivated behavior and pain-motivated behavior might arise, as suggested here by the decreased lying time and head against udder. Behaviors induced by persistent pain or sickness behavior can be quite similar and hard to distinguish without experimental manipulation of the experienced pain. Such studies would be highly relevant to elucidate consequences of painful diseases in terms of animal welfare.

\section{CONCLUSIONS}

Dairy cows expressed signs of classic sickness behavior, such as a decrease in feeding, ruminating, and self-grooming during the initial days after mastitis induction. Furthermore, the behavioral changes corresponded temporarily and correlated with the local and systemic clinical symptoms of disease; for example, SCC, milk yield, and rectal temperature. A decrease in feeding, ruminating, and self-grooming and an increased time spent standing idle seem representative behavioral changes in dairy cows with mastitis. The behavior was normalized within $48 \mathrm{~h}$ after infection. The present results can be used as a basis for further studies on motivational changes, preferences, and behavioral needs of diseased dairy cows, and thereby 
facilitate improved management of sick animals within the dairy industry.

\section{ACKNOWLEDGMENTS}

The authors gratefully acknowledge the financial support from Boehringer-Ingelheim (Ingelheim am Rhein, Germany) and the Landbrugets Hudefond Foundation (Copenhagen, Denmark) in making the video recordings possible. Furthermore, this work was supported by a Cutting Edge Genomics for Sustainable Animal Breeding (SABRE) research project co-financed by the European Commission within the 6th Framework Programme, contract No. FOOD-CT-2006-016250. The project was conducted as part of a mastitis experiment within the BIOSENS project, granted by the Danish Ministry of Food, Agriculture and Fisheries (Copenhagen, Denmark; Innovations Law), Lattéc A/S (Hillerød, Denmark), and the Danish Cattle Association (Aarhus, Denmark). The authors acknowledge the contributions to the acquisition of the data used in this research by the farm staff at Aarhus University Dairy Cattle facilities and by the technical staff at Aarhus University. Also greatly acknowledged are Julie S. Rasmussen, Henrik K. Andersen, Anton S. Jensen, and Niels K. Nielsen (Department of Animal Science, Faculty of Science and Technology, Aarhus University, Tjele, Denmark) for assisting with the processing of video recordings. Thanks go to Birthe Houbak, Eric L. Decker, and Jens Malmkvist (Department of Animal Science, Faculty of Science and Technology, Aarhus University, Tjele, Denmark) for the technical and statistical support. Great appreciation goes to Helle Daugaard Larsen, former Danish Institute for Food and Veterinary Research, (Copenhagen, Denmark) for kindly donating the bacteria used in the research.

\section{REFERENCES}

Aubert, A. 1999. Sickness and behaviour in animals: A motivational perspective. Neurosci. Biobehav. Rev. 23:1029-1036.

Bareille, N., F. Beaudeau, S. Billon, A. Robert, and P. Faverdin. 2003. Effects of health disorders on feed intake and milk production in dairy cows. Livest. Prod. Sci. 83:53-62.

Barrett, J. J., J. S. Hogan, W. P. Weiss, K. L. Smith, and L. M. Sordillo. 1997. Concentrations of alpha-tocopherol after intramammary infusion of Escherichia coli or lipopolysaccharide. J. Dairy Sci. 80:2826-2832.

Bradley, A. J. 2002. Bovine mastitis: An evolving disease. Vet. J. 164:116-128.

Broom, D. M. 2006. Behaviour and welfare in relation to pathology. Appl. Anim. Behav. Sci. 97:73-83.

Buitenhuis, B., C. M. Rontved, S. M. Edwards, K. L. Ingvartsen, and P. Sorensen. 2011. In-depth analysis of genes and pathways of the mammary gland involved in the pathogenesis of bovine Escherichia coli-mastitis. BMC Genomics 12:130.

Dantzer, R., and K. W. Kelly. 2007. Twenty years of research on cytokine-induced sickness behavior. Brain Behav. Immun. 21:153-160.
Gerjets, I., and N. Kemper. 2009. Coliform mastitis in sows: A review. J. Swine Health Prod. 17:97-105.

Gonzalez, L. A., B. J. Tolkamp, M. P. Coffey, A. Ferret, and I. Kyriazakis. 2008. Changes in feeding behavior as possible indicators for the automatic monitoring of health disorders in dairy cows. J. Dairy Sci. 91:1017-1028.

Hart, B. L. 1988. Biological basis of the behavior of sick animals. Neurosci. Biobehav. Rev. 12:123-137.

Ito, K., M. A. G. von Keyserlingk, S. J. LeBlanc, and D. M. Weary. 2010. Lying behavior as an indicator of lameness in dairy cows. J. Dairy Sci. 93:3553-3560.

Jensen, M. B., L. Munksgaard, L. J. Pedersen, J. Ladewig, and L. Matthews. 2004. Prior deprivation and reward duration affect the demand function for rest in dairy heifers. Appl. Anim. Behav. Sci. 88:1-11.

Jensen, M. B., L. J. Pedersen, and L. Munksgaard. 2005. The effect of reward duration on demand functions for rest in dairy heifers and lying requirements as measured by demand functions. Appl. Anim. Behav. Sci. 90:207-217.

Johnson, R. W. 2002. The concept of sickness behavior: A brief chronological account of four key discoveries. Vet. Immunol. Immunopathol. 87:443-450.

Kristensen, T. 1986. Method for estimation of body condition in dairy cows. Page 59-76 in Rep. No. DK8621430. Statens Husdyrbrugsforsoeg, Copenhagen, Denmark.

Krohn, C. C. 1994. Behavior of dairy-cows kept in extensive (loose housing pasture) or intensive (tie stall) environments. 3. Grooming, exploration and abnormal-behavior. Appl. Anim. Behav. Sci. 42:73-86.

Krohn, C. C., and L. Munksgaard. 1993. Behavior of dairy-cows kept in extensive (loose housing pasture) or intensive (tie stall) environments. 2. Lying and lying-down behaviour. Appl. Anim. Behav. Sci. $37: 1-16$.

Leslie, K., C. Kielland, and S. Millman. 2010. Is mastitis painful and is therapy for pain beneficial? Pages 114-130 in Proc. NMC Annual Meeting. NMC, Madison, WI.

Lohuis, J. A. C. M., W. Vanleeuwen, J. H. M. Verheijden, A. S. J. P. Vanmiert, and A. Brand. 1988. Effect of dexamethasone on experimental Escherichia coli mastitis in the cow. J. Dairy Sci. 71:2782-2789.

Milne, M. H., A. M. Nolan, P. J. Cripps, and J. L. Fitzpatrick. 2003. Assessment and alleviation of pain in dairy cows with clinical mastitis. Cattle Pract. 11:289-293.

Moelgaard, L. 2010. Effects of liver biopsy sampling on dairy cow behaviour. MS Thesis. Aarhus University, Denmark.

Niss, D. B., M. S. Herskin, A. M. Danscher, and M. B. Thoefner. 2009. Short communication: Rising and lying behavior of heifers before and after alimentary oligofructose overload. J. Dairy Sci. 92:617-620.

Pyörälä, S. 2003. Indicators of inflammation in the diagnosis of mastitis. Vet. Res. 34:565-578.

Rasmussen, D. B., K. Fogsgaard, C. M. Rontved, I. C. Klaas, and M. S. Herskin. 2011. Changes in thermal nociceptive responses in dairy cows following experimentally induced Escherichia coli mastitis. Acta Vet. Scand. 53:32.

Siivonen, J., S. Taponen, M. Hovinen, M. Pastell, B. J. Lensink, S. Pyörälä, and L. Hänninen. 2011. Impact of acute clinical mastitis on cow behaviour. Appl. Anim. Behav. Sci. 132:101-106.

Takeuchi, Y., T. Kikusui, and Y. Mori. 1995. Changes in the behavioral parameters following the lipopolysaccharide administration in goats. J. Vet. Med. Sci. 57:1041-1044.

Urton, G., M. A. G. von Keyserlingk, and D. M. Weary. 2005. Feeding behavior identifies dairy cows at risk for metritis. J. Dairy Sci. 88:2843-2849

Vels, L., C. M. Rontved, M. Bjerring, and K. L. Ingvartsen. 2009. Cytokine and acute phase protein gene expression in repeated liver biopsies of dairy cows with a lipopolysaccharide-induced mastitis. J. Dairy Sci. 92:922-934.

Weary, D. M., L. Niel, F. C. Flower, and D. Fraser. 2006. Identifying and preventing pain in animals. Appl. Anim. Behav. Sci 100:64-76. 